\title{
Two Case Reports of Hereditary Sensory Autonomic Neuropathy Type IV
}

\author{
Khairunnisa Mukhtiar ${ }^{1}$, Qurat-Ul-Ain Khalid ${ }^{1}$, Sanam Bano Rajper ${ }^{1}$ \\ ${ }^{1}$ Department of Pediatrics and Child Health, Aga Khan University Hospital Karachi, Pakistan
}

\begin{abstract}
Hereditary Sensory Autonomic Neuropathy type IV (HSAN-IV), previously known as congenital insensitivity to pain and anhidrosis (CIPA), is an uncommon condition that presents in infancy with repeated episodes of fever, loss of pain sensations and self-mutilation. We are reporting two patients from two different families. Both patients had history of recurrent fever, anhidrosis, and pain insensitivity and self-mutilation behavior. Both had delayed motor developmental milestones with cognitive impairment. Clinical diagnosis of HSAN type IV was made on the basis of history, clinical examination and excluding other possible causes. Diagnosis of this rare disease is commonly delayed and patients ultimately develop complications. As there is no definitive treatment, these patients and their families should receive proper education and counselling for rehabilitation.
\end{abstract}

Key Words: Hereditary Sensory Autonomic Neuropathy, Insensitivity to pain, Self-mutilation

$\begin{array}{ll}\text { Correspondence: } & \text { Article info: } \\ \text { Qurat-Ul-Ain Khalid } & \text { Received: August 31, 2020 } \\ \text { Email: quratulainkhalid78@hotmail.com } & \text { Accepted: December 10, 2020 }\end{array}$

Cite this case Report: Mukhtiar K, Khalid Q, Rajper SB. Two Case Reports of Hereditary Sensory Autonomic Neuropathy Type IV. J Islamabad Med Dental Coll. 2020; 9(4): 307-310 Doi: 10.35787/jimdc.v9i4.595

Funding Source: Nil

Conflict of Interest: Nil

\section{Introduction}

HSAN-IV is a very rare autosomal recessive disease. It is one of the degenerative disorders affecting the sensory as well as autonomic nerves. It affects the numbers and distribution of small myelinated and non-myelinated nerve fibers, which is manifested by decreased sensitivity in response to pain, touch and pressure in distal extremities. ${ }^{1}$ HSAN is caused by abnormal mutation of the neurotrophic tyrosine kinase receptor (NTRK) type 1 gene. This gene is responsible for nerve growth factor (NGF) effects, and it helps in the development of the nociceptive, sensory and sympathetic neurons during the embryological period. ${ }^{2}$ Symptoms of this disease begins in infancy. Common clinical presentations include anhidrosis, insensitivity to noxious stimuli leading to self-mutilating behavior, and intellectual disability. ${ }^{3}$ Patients with HSAN-IV are prone to develop multiple injuries, which lead to recurrent skin infections and deformities of bone. Because of insensitivity to pain, they produce severe oral mutilations like bite wounds, dental attrition, premature tooth loss, and ulcerations of skin. The most vulnerable areas for self-inflicted injuries are lips and oral mucosa. These oral manifestations are especially characteristic features in HSAN-IV.

The uncommon nature of this disease leads to a delayed diagnosis and development of further complications. There should be regular and careful examination of all four limbs for injuries. ${ }^{4,5}$ Here we 
are reporting two patients from two different families. Both went to multiple physicians and they were treated as pyrexia of unknown origin, given multiple oral and intravenous antibiotics but no definitive diagnosis was made.

\section{Case Reports}

\section{Patient 1}

A 12-year-old boy came in clinic with complaints of aggressive behavior and recurrent episodes of fever since infancy. There was also history of selfmutilating behavior, which started since infancy. Past history revealed repeated episodes of highgrade fever in hot weather that did not respond to antipyretics and antibiotics. Parents also give history of absence of crying during any kind of trauma and when parenteral antibiotics were given for fever. He was a product of consanguineous marriage and was healthy at the time of birth. There was a positive family history of similar illness in his elder brother who expired at the age of 10 year. All the other siblings were normal. On examination, he had mild developmental and speech delay. He had poor cognitive functions with an IQ below 70. He was withdrawn from school due to aggressive behavior and tendency for self-mutilation. The skin of palm and sole was thick with deformity of his fingernails and toenails (Figure 1).

Neurological examination revealed absence of response to temperature and painful stimuli. Deep tendon and plantar reflexes were normal. All cranial nerves were intact. Our initial differential diagnoses were Lesch-Nyhan syndrome and HSAN. On investigation, serum uric acid was normal, thus ruling out Lesch-Nyhan syndrome. Nerve conduction study was also normal. Patient was diagnosed as a case of HSAN-IV on the basis of typical history and clinical examination. Parents were counselled regarding the child's condition and benefits of lifelong supportive treatment.

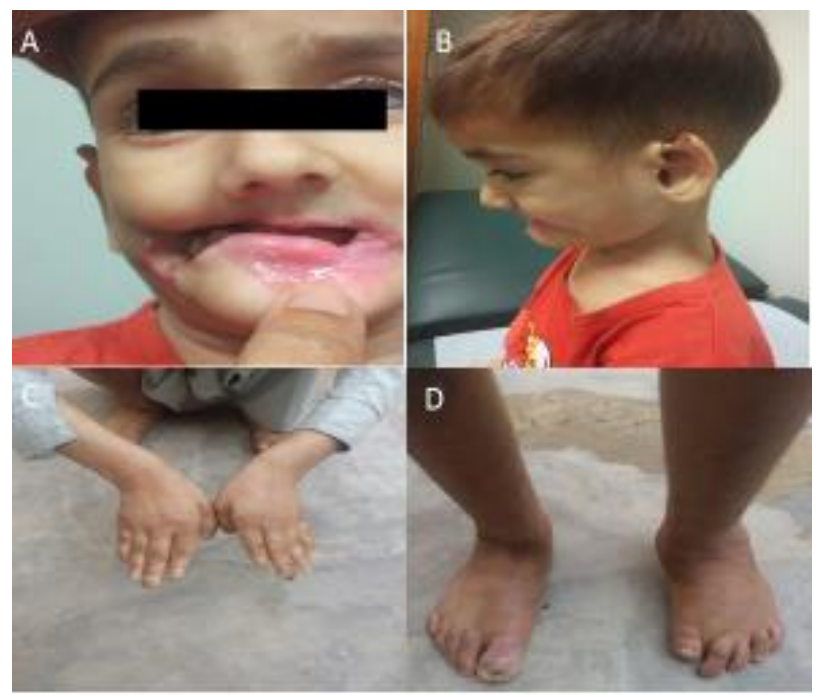

Figure 1: Patient 2 with self-mutilation injuries involving lips, angle of mouth, buccal mucosa (A) and ear pinna (B). Patient 1 with self-mutilation injuries of hands (C) and toes (D).

\section{Patient 2}

This 6-year-old boy was brought to the clinic by his parents with issue of delayed developmental milestones. He was the third child of the family and born from a consanguineous marriage. The child suffered from repeated fever episodes, frequently worsening in summers. Parents noticed that their child had absence of sweating even in the summer season, and he had poor responsiveness to painful stimulation.

He demonstrated self-mutilating behaviors causing injury to himself, including biting his tongue, lips and the lining of the inside of the mouth (buccal mucosa), finger tips and toes. In addition, pain insensitivity led to multiple injuries. Behavioral problems included irritability, hyperactivity, emotional lability, and episodes of anger. The first child of the family died at 8 years of life with similar issues and developed complicated pneumonia resulting in a fatal outcome. On physical examination, he had poor eye contact, selfmutilation injuries in the perioral area with damage to both upper and lower lips, angles of mouth and ear pinna (Figure 1). The deep tendon reflexes were 
normal and he had reduced sensitivity to pain and temperature. On investigations his uric acid was normal. Nerve conduction studies were not significant. Diagnosis of HSAN Type IV was made by considering the typical clinical symptoms, age of onset, and normal electrodiagnostic test.

\section{Discussion}

Here we report two case of HSAN-IV belonging to two different families. The patients identified here have a classical presentation of this disease. Until now, more than 20 genes have been identified which are associated with HSAN-IV phenotype, characterized by sensory and autonomic dysfunctions. ${ }^{6}$ Pain insensitivity, self-mutilation injuries and absence of sweat and tears are the hallmarks of this disorder. Other features in common with HSAN-IV are microcephaly, mental retardation, motor and speech delay and abnormal autonomic functions. ${ }^{7}$ Both patients had poor cognitive functions and positive family history of similar illness in siblings.

There are only few cases of HSAN-IV reported in the literature. Patients with HSAN-IV can live a normal life. As there is no curative treatment for HSAN-IV, parents should be educated to take precautions in daily life to ensure the safety of the child. They should regularly check for bruises and selfmutilation injuries. Patients should visit their physician regularly for complete examination to rule out possibility of any issues due to pain insensitivity, which can be detrimental in future. ${ }^{8}$ Self-mutilating behavior is accentuated by reduced pain sensitivity, rather, it may cause a pleasant sense instead of sense of pain. ${ }^{9}$ The major cause for death in patients with HSAN-IV are the issues that can be treated with early intervention and management. Heat stroke can be fatal in these patients because they cannot feel the heat and it can be easily underdiagnosed. ${ }^{10}$ One of our patients had auto-amputation of fingers due to self-mutilation injuries.
The main purpose of reporting these cases is to increase awareness among physicians about this syndrome so that an accurate diagnosis can be made without unnecessary investigations. This will also avoid unnecessary surgical intervention as only supportive treatment is required. Unfortunately, genetic analysis was not carried out in both our patients due to unavailability of this technique. We started conservative treatment along with family education and counselling to improve the quality of life of these patients.

\section{Conclusion}

Pain and temperature insensitivity, self-mutilation injuries, aggressive behavior, poor cognitive functions and positive family history were the hallmark features of our patients. Diagnosis of HSAN-IV is based on history, clinical examination, laboratory investigations, electrodiagnostic test and genetic testing, if available. As there is no known cure for this illness, conservative treatment along with family education and counselling is required to improve the quality of life of these patients.

\section{References}

1. Ashwin DP, Chandan GD, Jasleen HK, Rajkumar GC, Rudresh KB, Prashanth R. Hereditary sensory and autosomal peripheral neuropathy-type IV: case series and review of literature. Oral Maxillofac Surg. 2015; 19(2): 117-23. Doi: 10.1007/s10006-015-04865

2. Urfalioglu A, Arslan M, Duman Y, Gisi G, Oksuz G, Yildiz $\mathrm{H}$, et al. Anesthesia Procedure for Congenital Insensitivity to Pain in a Child with Anhidrosis Syndrome: A Rare Case. J Nippon Med Sch. 2017; 84(5): 237-40. Doi: 10.1272/jnms.84.237

3. Altassan R, Saud HA, Masoodi TA, Dosssari HA, Khalifa $\mathrm{O}$, Al-Zaidan $\mathrm{H}$, et al. Exome sequencing identifies novel NTRK1 mutations in patients with HSAN-IV phenotype. Am J Med Genet A. 2017; 173(4): 1009-16. Doi: 10.1002/ajmg.a.38120

4. Gaur N, Meel R, Anjum S, Singh P. Hereditary sensory and autonomic neuropathy in a male child: 'The other side of not feeling pain'. BMJ Case Rep. 2018; 2018. Doi: $10.1136 /$ bcr-2018-226873 
5. Paduano S, lodice G, Farella M, Silva R, Michelotti A. Orthodontic treatment and management of limited mouth opening and oral lesions in a patient with congenital insensitivity to pain: case report. J Oral Rehabil. 2009; 36(1): 71-8. Doi: 10.1111/j.13652842.2008.01887.x

6. Yuan JH, Hashiguchi A, Yoshimura A, Sakai N, Takahashi MP, Ueda T, et al. WNK1/HSN2 founder mutation in patients with hereditary sensory and autonomic neuropathy: A Japanese cohort study. Clin Genet. 2017; 92(6): 659-63. Doi: 10.1111/cge.13037

7. Schulman $H$, Tsodikow V, Einhorn M, Levy $Y$, Shorer $Z$, Hertzanu Y. Congenital insensitivity to pain with anhidrosis (CIPA): the spectrum of radiological findings. Pediatr Radiol. 2001; 31(10): 701-5. Doi: $10.1007 / \mathrm{s} 002470100506$
8. Daneshjou K, Jafarieh H, Raaeskarami SR. Congenital Insensitivity to Pain and Anhidrosis (CIPA) Syndrome; A Report of 4 Cases. Iran J Pediatr. 2012; 22(3): 4126. PMID: 23400697

9. Baghdadi T, Sadeghifar A, Mortazavi SMJ, Espandar R. Indifference to pain syndrome in a twelve-year-old boy (case report). Tehran Univ Med J. 2007; 4. PMID: 27247588

10. Lafreniere RG, MacDonald ML, Dube MP, MacFarlane J, O'Driscoll M, Brais B, et al. Identification of a novel gene (HSN2) causing hereditary sensory and autonomic neuropathy type II through the Study of Canadian Genetic Isolates. Am J Hum Genet. 2004; 74(5): 1064-73. 